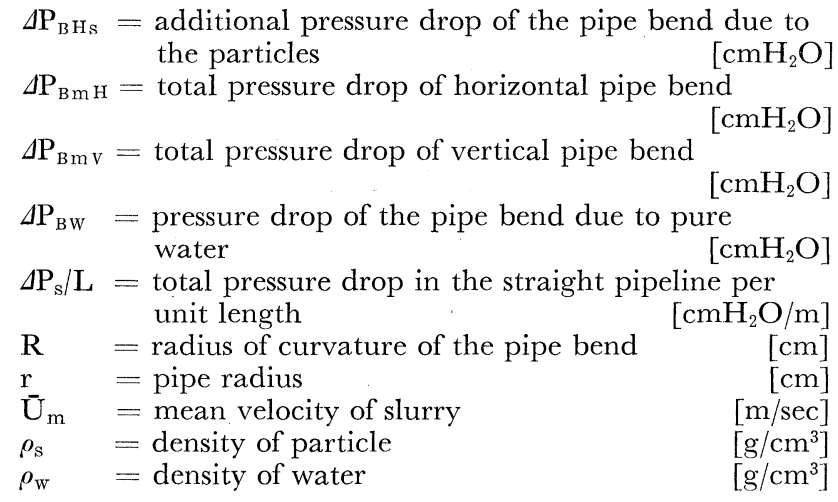

\section{Literature Cited}

1) Ayukawa, K.: Trans. J.S.M.E., 35, 563 (1969)

2) Barth, W.: Chemie. Ing. Techn., 26, 29 (1954)

3) Durand, R.: La Houille Blanche, 8, 124 (1953)
4) Ito, H.: Mem. Inst. High Sp. Mech., 14, No. 137, Tohoku University (1957)

5) Ito, H. : Mem. Inst. High Sp. Mech., 15, No. 141, Tohoku University (1960)

6) Kuzuhara, S.: Trans. J.S. M.E., 31, 243 (1965)

7) Mori, Y. and A. Suganuma: Kagaku Kōgaku, 30, 421 (1966)

8) Newitt, D. M., J. F. Richardson, M. Abbott and R. B. Turtle: Trans. Instn. Chem. Engrs., 33, 93 (1955)

9) Newitt, D. M., J. F. Richardson and B. J. Gliddon: ibid., 39, 93 (1961)

10) Sugawara, S., S. Kikkawa and J. Oizumi: Trans. J.S.M.E., 27, 638 (1961)

11) Toda, M., H. Konno, S. Saito and S. Maeda: Kagaku Kōgaku, 33, 67 (1969)

12) Uematu, T. and T. Kano: Trans. J.S. M. E., 28, 164 (1962)

13) Wilson, W. E.: Trans. Amer. Soc. Civ. Engrs., 107, 268 (1942)

14) Weidner, G.: Forsch. Ing. Wessen., 21, 145 (1955)

15) Yoshizawa, S., T. Kawashima and K. Noda: MMIJ, 80, No. 918, 1047 (1964)

\title{
COLUMN EFFICIENCIES OF RECTIFYING COLUMN WITH LIQUID MIXING ON PLATE*
}

\author{
KAKUSABURO ONDA, HIROSHI TAKEUCHI \\ AND KATSUROKU TAKAHASHI \\ Department of Chemical Engineering, Nagoya University, \\ Nagoya, Japan
}

\begin{abstract}
Relation between column efficiency and plate efficiency in a rectifying column is investigated by considering the liquid mixing on the plate. Under the assumption that the vapor on the plate is in equilibrium with the liquid at the center of the plate, the column efficiency is derived as a function of the plate efficiency, $\lambda(=m V / L)$ and the mixing parameter $F$ for the case where the equilibrium curve is given as a straight line. It is shown that the results can be applied by using the mean value of $\lambda$ in case the equilibrium curve is not a straight line.
\end{abstract}

\section{Introduction}

The column efficiency $E_{T}$, a ratio of the theoretical plate numbers to the practical plate numbers, is very important for the design of a rectifying column. However, there is no strict method to calculate column efficiency. Lewis ${ }^{9}$ gave the column efficiency as a function of Murphree's plate efficiency $\left(E_{M V}\right)_{1}$ and $\lambda(=m V / L)$ when the equilibrium curve is a straight line. Murphree's plate efficiency $\left(E_{M V}\right)_{1}$, defined with the vapor composition in equilibrium with the liquid leaving the plate, depends upon $\lambda^{13,14}$. Also, Lewis's relation does not show clearly the dependence of $E_{T}$ on $\lambda$, which is a function of reflux ratio. Onda

* Received on July 8, 1971

Presented at 4th Autumn Meeting of the Society of Chemical Engineers, Japan, October 6, 1970 and Kobayashi ${ }^{13}$ defined the modified plate efficiency $\left(E_{M V}\right)_{1 / 2}$ based on the vapor composition in equilibrium with the liquid at the center of the plate, and showed that $\left(E_{M V}\right)_{1 / 2}$ is reasonable and depends littel upon $\lambda$.

In our previous paper ${ }^{14)}$, the relation between column efficiency and modified plate efficiency $\left(E_{M V}\right)_{1 / 2}$ was derived under the assumption that the liquid flows on the plate in plug flow. In this paper, column efficiency is discussed as a function of the reflux ratio. Further, taking into account liquid mixing on the plate, the column efficiency $E_{T}$ has been derived as a function of $\left(E_{M V}\right)_{1 / 2}, \lambda$ and the mixing parameter $F$. The plate efficiency $\left(E_{M L}\right)_{1 / 2}$ based on the composition of liquid phase has been also expressed as a function of $\left(E_{M V}\right)_{1 / 2}, \lambda$ and $F$, because the plate efficiency based on the composition of liquid phase is more often used. 


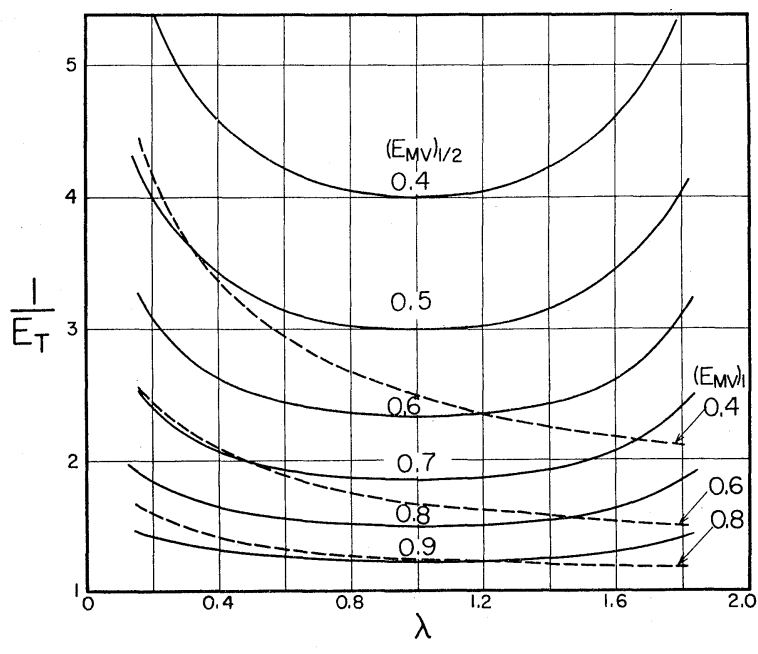

Fig. 1 Relation between $1 / E_{T}$ and $\lambda$ with parameter $E_{M V}$

\section{Column Efficiency and Reflux Ratio}

Under the assumption that the equilibrium curve is a straight line, the column efficiency was given by Lewis $^{9}$.

$$
\frac{1}{E_{T}}=\frac{\ln \lambda}{\ln \left\{1+\left(E_{M V}\right)_{1}(\lambda-1)\right\}}
$$

This relation is shown in Fig. 1 with broken lines for various values of $\left(E_{M V}\right)_{1}$. As pointed out by Onda and Kobayashi ${ }^{13)},\left(E_{M V}\right)_{1}$ depends on $\lambda$ and the dependency increases with increase of Peclet's number $N_{P e}$. Therefore, the larger the diameter of the rectifying column, the greater the dependence of $\left(E_{M V}\right)_{1}$ on $\lambda$, and the relation presented by Eq. (1) is not clear.

Instead of vapor composition in equilibrium with liquid leaving the plate, vapor composition $y_{n}^{*}$ in equilibrium with liquid at the center of the plate is used to define the plate efficiency.

$$
\left(E_{M V}\right)_{1 / 2}=\frac{y_{n}-y_{n-1}}{y_{n}^{*}-y_{n-1}}
$$

Then the modified plate efficiency $\left(E_{M V}\right)_{1 / 2}$ agrees with the point efficiency $E_{O G}$ within $4 \%$ error for $\lambda E_{O G}<1$, and the dependence of $\left(E_{M V}\right)_{1 / 2}$ on $\lambda$ is very small ${ }^{13)}$. In our previous paper ${ }^{14)}$, the column efficiency was derived as a function of $\left(E_{M V}\right)_{1 / 2}$ and $\lambda$ under the assumption that the equilibrium curve is given by a straight line and that liquid flows on the plate in plug flow.

$$
\frac{1}{E_{T}}=\frac{\log \frac{\lambda}{2-\lambda}}{\log \frac{\lambda\left(E_{M V}\right)_{1 / 2}-2\left(E_{M V}\right)_{1 / 2}+2}{2-\lambda\left(E_{M V}\right)_{1 / 2}}} .
$$

$1 / E_{T}$ becomes minimum at $\lambda=1$ for a fixed value of $\left(E_{M V}\right)_{1 / 2}$, as shown by the solid line in Fig. 1, and this is confirmed by differentiating Eq.(3).

$$
\lim _{\lambda \rightarrow 1} \frac{d\left(1 / E_{T}\right)}{d \lambda}=0
$$

As mentioned above, the dependence of $\left(E_{M V}\right)_{1 / 2}$ upon $\lambda$ is small, so Eq.(3) gives the relation between

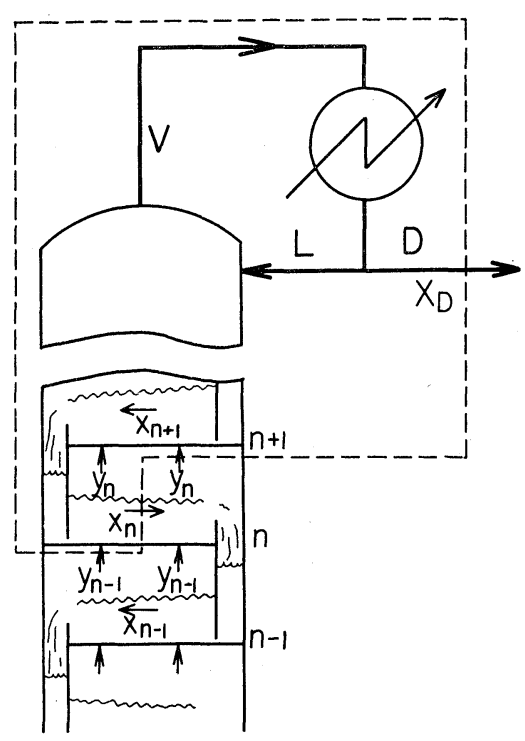

Fig. 2 Schematic diagram of rectifying section of continuous rectifying column

$1 / E_{T}$ and $\lambda$ correctly.

For $\lambda=1, L / V$ is equal to $m$, that is, the slope of the operating line is equal to that of the equilibrium curve. Therefore, under the assumption that liquid flow on the plate in plug flow, for a fixed value of $\left(E_{M V}\right)_{1 / 2}$ the column efficiency becomes maximum when the column is operated with the following relation.

$$
\frac{R}{R+1}=m
$$

In general, the equilibrium curve is not a straight line, and the value of $\lambda$ varies with the composition. The column efficiency $E_{T}$ is calculated by Eq.(3) with the mean value of $\lambda$. In this calculation, since $1 / E_{T}$ is minimum at $\lambda=1$ as described above, the composition range is divided into two regions where $\lambda \leqq 1$ and $\lambda>1$ and the column efficiency can be calculated accurately ${ }^{14)}$.

\section{Column Efficiency with Liquid Mixing}

Practically, the liquid on the plate is mixed by bubbling of the vapor. Taking liquid mixing into account, the following equation is derived from the material balance for the system shown by the broken line in Fig. 2.

$$
\begin{aligned}
\frac{y_{n-1}+y_{n}}{2} & =\left(\frac{L}{V}\right)\left(x_{n}-\left.\frac{D_{e} A \rho_{L}}{L} \frac{d x}{d z}\right|_{z=Z / 2}\right)+\left(\frac{D}{V}\right) x_{D} \\
& =\left(\frac{L}{V}\right)\left(x_{n}-\left.\frac{1}{N_{P e}} \frac{d x}{d w}\right|_{w=1 / 2}\right)+\left(\frac{D}{V}\right) x_{D}
\end{aligned}
$$

The composition profile of the liquid on the plate is given as follows ${ }^{13)}$.

$$
\frac{x-x_{n-1}^{*}}{x_{n}-x_{n-1}^{*}}=\frac{\exp \left\{\left(\eta+N_{P e}\right)\left(w-\frac{1}{2}\right)\right\}}{1+\frac{\eta+N_{P e}}{\eta} \exp \left(\eta+\frac{N_{P e}}{2}\right)}
$$


Table 1 Value of $F$ in practical columns

\begin{tabular}{lcccc} 
System & Acetone-Benzene $^{1)}$ & $n$, Pentane- $p$, Xylene $^{1)}$ & Methanol-Toluene $^{2)}$ & $i$, Octane-Toluene $^{10)}$ \\
\hline$E_{O G}$ & $0.702 \sim 0.866$ & $0.639 \sim 0.843$ & $0.605 \sim 0.870$ & $0.553 \sim 0.721$ \\
$\lambda$ & $0.293 \sim 2.58$ & $1.90 \sim 10.6$ & $4.10 \sim 18.7$ & $0.636 \sim 0.764$ \\
$N_{P e}$ & $12.0 \sim 35.4$ & $9.37 \sim 12.32$ & $5.15 \sim 7.93$ & $23.7 \sim 36.5$ \\
$F$ & $0.011 \sim 0.087$ & $0.116 \sim 0.480$ & $0.374 \sim 1.00$ & $0.010 \sim 0.016$ \\
\hline
\end{tabular}

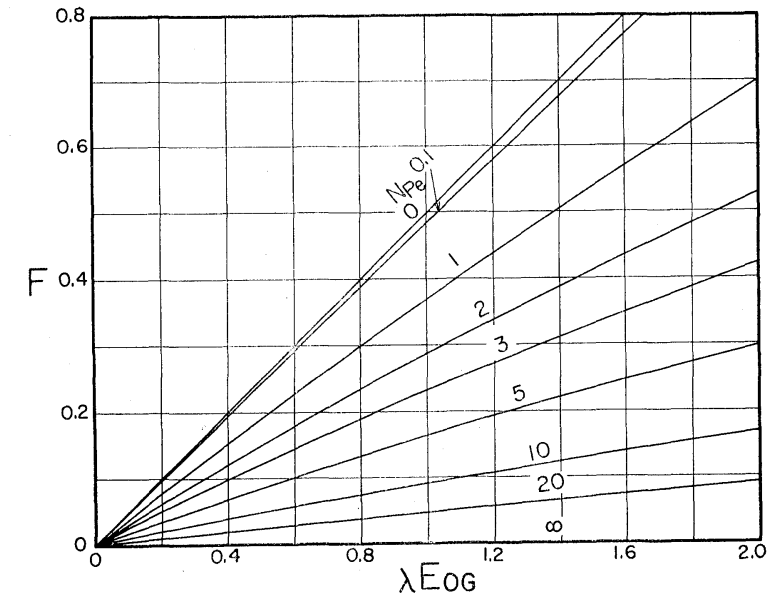

Fig. 3 Relation between $F$ and $\lambda E_{O G}$ with parameter $N_{P e}$

$$
+\frac{\exp \left\{\left(\frac{\eta+N_{P e}}{2}\right)-\eta(w-1)\right\}}{\exp \left(\eta+\frac{N_{P e}}{2}\right)+\frac{\eta}{\eta+N_{P e}}}
$$

where

$$
\eta=\frac{N_{P e}}{2}\left(\sqrt{1+\frac{4 \lambda E_{O G}}{N_{P e}}}-1\right)
$$

Eq. (7) is differentiated with $w$, and the result is substituted into Eq.(6).

$$
\frac{y_{n-1}+y_{n}}{2}=\left(\frac{L}{V}\right)\left\{x_{n}+(F)\left(x_{n}-x_{n-1}^{*}\right)\right\}+\left(\frac{D}{V}\right) x_{D}
$$

where

$$
F=\frac{\eta\left(\eta+N_{P e}\right)\left\{\exp \left(\eta+N_{P e} / 2\right)-1\right\}}{N_{P e}\left\{\eta+\left(\eta+N_{P e}\right) \exp \left(\eta+\frac{N_{P e}}{2}\right)\right\}}
$$

The relation between $F$ and $\lambda E_{O G}$ is shown by parameter $N_{P e}$ in Fig. 3. For plug flow of the liquid, the value of $F$ is zero. It increases with increase of mixing degree, i.e., the decrease of $N_{P e}$, and becomes $\lambda E_{O G} / 2$ for complete mixing of the liquid. The values of $F$ are shown in Table 1 for practical cases. From Table 1 , it is seen that $F$ values are very small and that plug flow occurs more frequently in practical columns.

With the same assumption as Lewis made, i.e., the equilibrium curve is a straight line, and the plate efficiency is constant over the column, a relation between column efficiency $E_{T}$ and modified plate efficiency $\left(E_{M V}\right)_{1 / 2}$ is derived as follows.

The equilibrium curve is assumed as a straight line.

$$
y^{*}=m x+b_{1}
$$

And the operating line is expressed by

VOL. 5 NO. $1 \quad 1972$

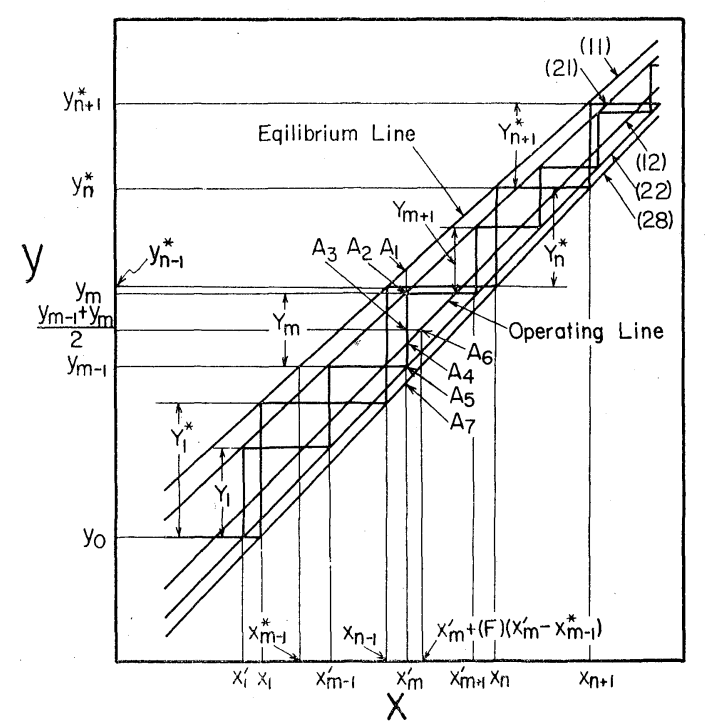

Fig. 4 Illustration to determine the number of theoretical and practical plates

$$
y=\left(\frac{L}{V}\right) x+\left(\frac{D}{V}\right) x_{D}
$$

These lines are shown in Fig. 4. The horizontal line of $y=\left(y_{m-1}+y_{m}\right) / 2$ intersects the operating line at a point $A_{6}$, and the point expresses $\left\{\left(y_{m-1}+y_{m}\right) / 2\right.$, $\left.x_{m}^{\prime}+(F)\left(x_{m}^{\prime}-x_{m-1}^{*}\right)\right\}$ from Eqs. (9) and (12). From the definition of plate efficiency

$$
\begin{aligned}
\overline{A_{2} A_{5}} & =y_{m}-y_{m-1}=\left(E_{M V}\right)_{1 / 2} \overline{A_{1} A_{5}} \\
& =m\left(E_{M V}\right)_{1 / 2}\left(x_{m}^{\prime}-x_{m-1}^{*}\right) \\
\overline{A_{3} A_{4}} & =(1 / 2) \overline{A_{2} A_{5}}-\overline{A_{4} A_{5}} \\
& =(m / 2)\left(E_{M V}\right)_{1 / 2}\left(x_{m}^{\prime}-x_{m-1}^{*}\right)-\overline{A_{4} A_{5}}
\end{aligned}
$$

The slope of the operating line is given by

$$
\frac{L}{V}=\frac{\overline{A_{3} A_{4}}}{\overline{A_{3} A_{6}}}=\frac{\overline{A_{3} A_{4}}}{(F)\left(x_{m}^{\prime}-x_{m-1}^{*}\right)}
$$

Eq.(14) is substituted into Eq.(15), and rearranged to

$$
\overline{A_{4} A_{5}}=\left\{\frac{m}{2}\left(E_{M V}\right)_{1 / 2}-(F)\left(\frac{L}{V}\right)\right\}\left(x_{m}^{\prime}-x_{m-1}^{*}\right)
$$

From Eqs. (13) and (16)

$$
\begin{aligned}
\frac{\overline{A_{4} A_{5}}}{\overline{A_{2} A_{4}}} & =\frac{\overline{A_{4} A_{5}}}{\overline{A_{2} A_{5}}-\overline{A_{4} A_{5}}} \\
& =\frac{\left\{\frac{m}{2}\left(E_{M V}\right)_{1 / 2}-(F)\left(\frac{L}{V}\right)\right\}\left(x_{m}^{\prime}-x_{m-1}^{*}\right)}{\left\{\frac{m}{2}\left(E_{M V}\right)_{1 / 2}+(F)\left(\frac{L}{V}\right)\right\}\left(x_{m}^{\prime}-x_{m-1}^{*}\right)} \\
& =\frac{\lambda\left(E_{M V}\right)_{1 / 2}-2 F}{\lambda\left(E_{M V}\right)_{1 / 2}+2 F}
\end{aligned}
$$

The modified plate efficiency is expressed in Fig. 4 
as

$$
\left(E_{M V}\right)_{1 / 2}=\frac{\overline{A_{2} A_{5}}}{\overline{A_{1} A_{5}}}=\frac{\overline{A_{2} A_{4}}+\overline{A_{4} A_{5}}}{\overline{A_{1} A_{4}}+\overline{A_{4} A_{5}}}
$$

From Eqs.(17) and (18), following relations are derived.

$$
\begin{aligned}
& \frac{\overline{A_{2} A_{4}}}{\overline{A_{1} A_{4}}}=\frac{\lambda\left(E_{M V}\right)_{1 / 2}+2 F}{\lambda\left\{2-\left(E_{M V}\right)_{1 / 2}\right\}+2 F} \\
& \frac{\overline{A_{4} A_{5}}}{\overline{A_{1} A_{4}}}=\frac{\lambda\left(E_{M V}\right)_{1 / 2}-2 F}{\lambda\left\{2-\left(E_{M V}\right)_{1 / 2}\right\}+2 F}
\end{aligned}
$$

Under the assumption that $\left(E_{M V}\right)_{1 / 2}$ is constant over the column, the straight lines (21) and (22), which satisfy Eqs.(19) and (20) for any value of $x$, are drawn in Fig. 4.

$$
\begin{aligned}
& y_{m}=a_{3} x_{m}^{\prime}+b_{3} \\
& y_{m-1}=a_{4} x_{m}^{\prime}+b_{4}
\end{aligned}
$$

The constants are determined as follows.

$$
\begin{aligned}
& \frac{a_{3}-\left(\frac{L}{V}\right)}{m-\left(\frac{L}{V}\right)}=\frac{b_{3}-\left(\frac{D}{V}\right) x_{D}}{b_{1}-\left(\frac{D}{V}\right) x_{D}}=\frac{\lambda\left(E_{M V}\right)_{1 / 2}+2 F}{\lambda\left\{2-\left(E_{M V}\right)_{1 / 2}\right\}+2 F} \\
& a_{3}=\left(\frac{L}{V}\right) \frac{\lambda\left[2\left\{1-\left(E_{M V}\right)_{1 / 2}\right\}+\lambda\left(E_{M V}\right)_{1 / 2}+2 F\right]}{\lambda\left\{2-\left(E_{M V}\right)_{1 / 2}\right\}+2 F} \\
& b_{3}=\frac{\lambda\left[2\left\{1-\left(E_{M V}\right)_{1 / 2}\right\}(D / V) x_{D}+b_{1}\left(E_{M V}\right)_{1 / 2}\right]+2 b_{1} F}{\lambda\left\{2-\left(E_{M V}\right)_{1 / 2}\right\}+2 F}
\end{aligned}
$$

Similarly,

$$
\begin{aligned}
& a_{4}=\left(\frac{L}{V}\right) \frac{\lambda\left[\left\{2-\lambda\left(E_{M V}\right)_{1 / 2}\right\}+2 F\right]}{\lambda\left\{2-\left(E_{M V}\right)_{1 / 2}\right\}+2 F} \\
& b_{4}=\frac{\lambda\left\{2\left(\frac{D}{V}\right) x_{D}-b_{1}\left(E_{M V}\right)_{1 / 2}\right\}+2 b_{1} F}{\lambda\left\{2-\left(E_{M V}\right)_{1 / 2}\right\}+2 F}
\end{aligned}
$$

For ideal plates, Eq.(22) is rewritten as:

$$
y_{n-1}^{*}=a_{2} x_{n}+b_{2}
$$

where

$$
\begin{aligned}
& a_{2}=\left(\frac{L}{V}\right) \frac{\lambda\left\{2-\lambda+2(F)_{E O G=1}\right\}}{\lambda+2(F)_{E O G=1}} \\
& b_{2}=\frac{\lambda\left\{2\left(\frac{D}{V}\right) x_{D}-b_{1}\right\}+2 b_{1}(F)_{E O G=1}}{\lambda+2(F)_{E O G=1}}
\end{aligned}
$$

The number of theoretical plates is determined by stepwise construction between the lines (11) and (28) in Fig. 4, and $Y_{n}^{*}$ and $Y_{n+1}^{*}$ are given by

$$
\begin{aligned}
& Y_{n}^{*}=y_{n}^{*}-y_{n-1}^{*}=\left(m-a_{2}\right) x_{n}+\left(b_{1}-b_{2}\right) \\
& Y_{n+1}^{*}=y_{n+1}^{*}-y_{n}^{*}=\left(m-a_{2}\right) x_{n+1}+\left(b_{1}-b_{2}\right)
\end{aligned}
$$

The slope of line (28) is given by

$$
a_{2}=\frac{Y_{n}^{*}}{x_{n+1}-x_{n}}
$$

From Eqs.(31), (32) and (33), the following relation is obtained

$$
Y_{n+1}^{*}=\left(m-a_{2}\right)\left\{\frac{Y_{n}^{*}}{a_{2}}+x_{n}\right\}+\left(b_{1}-b_{2}\right)=\frac{m}{a_{2}} Y_{n}^{*}
$$

Thus, the series $\left\{Y_{n}^{*}\right\}$ is a geometrical progression and the summation of the series is

$$
(S U M)_{N}=\sum_{1}^{N} Y_{n}^{*}=\frac{Y_{1}^{*}\left(1-r^{* N}\right)}{1-r^{*}}
$$

where

$$
r^{*}=\frac{m}{a_{2}}=\frac{\lambda+2(F)_{E O G=1}}{2-\lambda+2(F)_{E_{O G}=1}}
$$

On the other hand, the number of practical plates is determined by stepwise construction between lines (21) and (22), as shown in Fig. 4. In the same way as for $Y_{n}^{*}$, the realtion between $Y_{m}$ and $Y_{m+1}$ is derived.

$$
Y_{m+1}=\frac{a_{3}}{a_{4}} Y_{m}=\frac{2\left\{1-\left(E_{M V}\right)_{1 / 2}\right\}+\lambda\left(E_{M V}\right)_{1 / 2}+2 F}{2-\lambda\left(E_{M V}\right)_{1 / 2}+2 F} Y_{m}
$$

The summation of geometrical series $\left\{Y_{m}\right\}$ is

$$
(S U M)_{M}=\frac{Y_{1}\left(1-r^{M}\right)}{1-r}
$$

where

$$
r=\frac{2\left\{1-\left(E_{M V}\right)_{1 / 2}\right\}+\lambda\left(E_{M V}\right)_{1 / 2}+2 F}{2-\lambda\left(E_{M V}\right)_{1 / 2}+2 F}
$$

The starting point of the stepwise constructions for both theoretical and practical cases is chosen at $y_{0}$. $Y_{1}^{*}$ and $Y_{1}$ are given by the following relations as shown in Fig. 4.

$$
\begin{aligned}
Y_{1}^{*} & =\left(m-a_{2}\right) \frac{y_{0}-b_{2}}{a_{2}}+\left(b_{1}-b_{2}\right) \\
& =\frac{2\left\{(\lambda-1) y_{0}+b_{1}-\lambda\left(\frac{D}{V}\right) x_{D}\right\}}{2-\lambda+2(F)_{E O G=1}} \\
Y_{1} & =\frac{2\left(E_{M V}\right)_{1 / 2}\left\{(\lambda-1) y_{0}+b_{1}-\lambda\left(\frac{D}{V}\right) x_{D}\right\}}{2-\lambda\left(E_{M V}\right)_{1 / 2}+2 F}
\end{aligned}
$$

After equating $(S U M)_{N}=(S U M)_{M}$, Eqs. $(35) \sim(41)$ are substituted and arranged as follows.

$$
r^{* N}=r^{M}
$$

The column efficiency $E_{T}$, the ratio of the theoretical plates to the practical plates, is given by

$$
\begin{gathered}
\frac{1}{E_{T}}=\frac{M}{N}=\frac{\log r^{*}}{\log r} \\
=\frac{\log \frac{\lambda+2(F)_{E o G=1}}{2-\lambda+2(F)_{E_{o G}=1}}}{\log \frac{2\left\{1-\left(E_{M V}\right)_{1 / 2}\right\}+\lambda\left(E_{M V}\right)_{1 / 2}+2 F}{2-\lambda\left(E_{M V}\right)_{1 / 2}+2 F}}
\end{gathered}
$$

With Eq.(43) the column efficiency can be calculated for any degree of liquid mixing on the plate. For plug flow of liquid on the plate, $F=0$, and Eq. (43) coincides with Eq.(3). On the other hand, for complete mixing of liquid

$$
F=\frac{\lambda E_{O G}}{2}=\frac{\lambda\left(E_{M V}\right)_{1 / 2}}{2}=\frac{\lambda\left(E_{M V}\right)_{1}}{2}
$$

and Eq.(43) coincides with Lewis's relation as follows.

$$
\begin{aligned}
\frac{1}{E_{T}} & =\frac{\log \lambda}{\log \left\{1-\left(E_{M V}\right)_{1 / 2}+\lambda\left(E_{M V}\right)_{1 / 2}\right\}} \\
& =\frac{\log \lambda}{\log \left\{1-\left(E_{M V}\right)_{1}+\lambda\left(E_{M V}\right)_{1}\right\}}
\end{aligned}
$$

For $\left(E_{M V}\right)_{1 / 2}=0.5,1 / E_{T}$ is calculated by Eq.(43) and shown by parameter $N_{P e}$ in Fig. 5. Though $1 / E_{T}$ is minimum at $\lambda=1$ for plug flow of liquid $\left(N_{P_{e}}=\infty\right)$, with the decrease of $N_{P e}$ the minimum point shifts to the right hand side, i.e., larger value of $\lambda$. Fig. 5 shows that $1 / E_{T}$ decreases with increase of mixing degree, and it seems that for a constant value of $\left(E_{M V}\right)_{1 / 2}$ the stronger the mixing degree, 


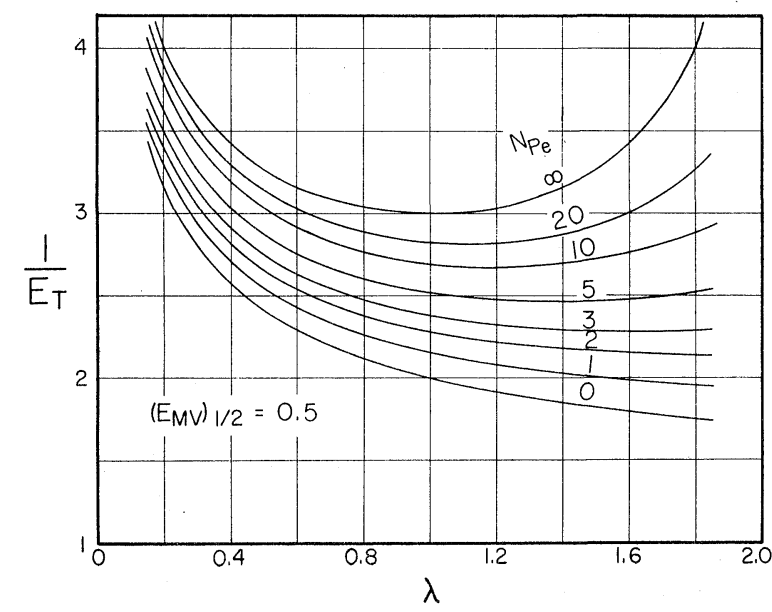

Fig. 5 Values of $1 / E_{T}$ calculated by Eq. (43) with parameter $N_{P e}$ for $\left(E_{M V}\right)_{1 / 2}=0.5$

the smaller the number of practical plates. However, the number of theoretical plates varies with the degree of liquid mixing, and the dependence of the number of practical plates on the mixing degree cannot be determined from $1 / E_{T}$ only. For example, in the case of $\lambda=1$ in Fig. 5, $1 / E_{T}$ for complete mixing is $2 / 3$ times that for plug flow of liquid. The number of theoretical plates for complete mixing is twice that for plug flow. As a result, the number of practical plates for complete mixing is larger by $4 / 3$ times than that for plug flow. Generally, it can be concluded that the number of practical plates to separate the mixture into desired products increases with the mixing degree.

Eq.(43) has been derived under the assumption that the equilibrium curve is a straight line. The equilibrium curve, however, is not a straight line usually. For the case when $\alpha=5, L / V=1$ and $N_{P e}=5$ the graphical method to determine the numbers of theoretical and practical plates is shown in Fig. 6 . The curve (28)' is drawn so that the following relation is satisfied with the point $A_{7}$ on the curve.

$$
\frac{\overline{A_{4} A_{7}}}{\overline{A_{1} A_{4}}}=\frac{\lambda-2(F)_{E o \sigma=1}}{\lambda+2(F)_{E O G=1}}
$$

which is a special case of Eq.(20) (i.e., for $\left(E_{M V}\right)_{1 / 2}=$ $\left.E_{O G}=1\right)$. The number of theoretical plates $N$ determined by stepwise construction between the equilibrium curve and the curve $(28)^{\prime}$ is 2.53 for $x=0.05 \sim$ 0.95. The curves $(21)^{\prime}$ and $(22)^{\prime}$ are drawn for the case of $\left(E_{M V}\right)_{1 / 2}=0.6$ to satisfy Eqs. (19) and (20), respectively. The practical plates $M$ determined by stepwise construction between curves $(21)^{\prime}$ and $(22)^{\prime}$ is 5.52. With this graphical method, $1 / E_{T}$, which is the ratio of $M$ to $N$, is 2.18. On the other hand, $1 / E_{T}$ calculated by Eq. (43) with the mean value of $\lambda$ for the case described above is 2.15 , and the coincidence with the graphical method is satisfactory. In this calculation, the composition range is divided into two regions where $\lambda \leqq 1$ and $\lambda>1$ in the same way as in the previous paper ${ }^{14)}$. In Fig. 7, $1 / E_{T}$

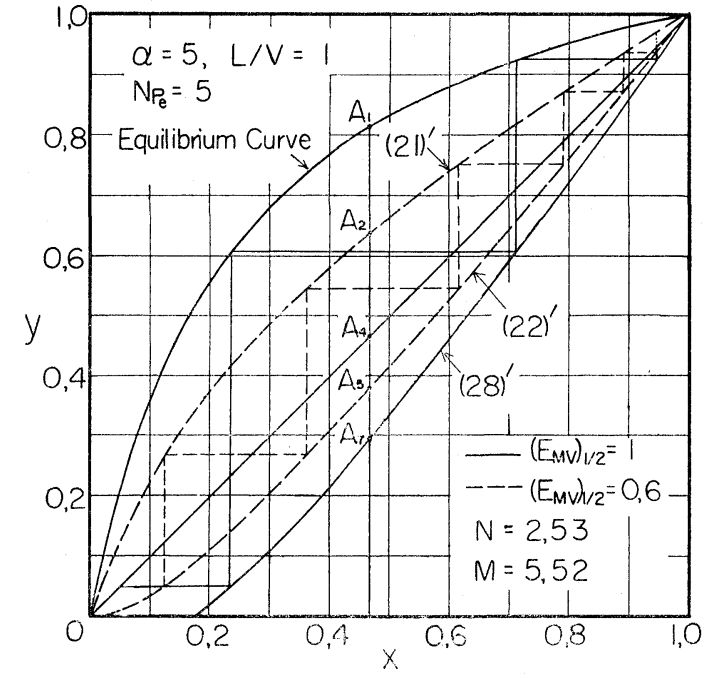

Fig. 6 Stepwise construction to determine the number of theoretical plates and that of practical plates

Table 2 Comparison of estimated plate efficiencies and experimental ones

\begin{tabular}{|c|c|c|c|c|c|c|}
\hline $\begin{array}{l}\text { Run No. } \\
\left(E_{M L}\right)_{1, \text { exp. }} \\
\left(E_{M V}\right)_{1 / 2, \text { ex }}^{\prime}\end{array}$ & & $\begin{array}{l}1 \\
0.77 \\
0.677\end{array}$ & $\begin{array}{l}2 \\
0.61 \\
0.620\end{array}$ & $\begin{array}{l}3 \\
0.82 \\
0.689\end{array}$ & $\begin{array}{l}10 \\
0.78 \\
0.669\end{array}$ & $\begin{array}{l}\text { mean } \\
\text { error } \\
{[\%]}\end{array}$ \\
\hline & Delaware $^{1)}$ & 0.91 & 0.76 & 1.00 & 1.01 & 19.0 \\
\hline & Delav & 0.85 & 0.87 & 0.82 & 0.74 & 11.2 \\
\hline & Michigan $^{2)}$ & 0.27 & 0.11 & 0.42 & 0.49 & 203 \\
\hline & Gerster $^{6}$ & 0.26 & 0.28 & 0.32 & 0.32 & 156 \\
\hline & $\begin{array}{l}\text { Drickamer } \\
\text { et al } \text {. }^{\text {) }}\end{array}$ & 0.42 & 0.47 & 0.46 & 0.46 & 65.0 \\
\hline$\left(E_{M L}\right)_{1, \text { cal. }}$ & $\mathrm{O}^{\prime}$ Connell ${ }^{11)}$ & 0.43 & 0.47 & 0.47 & 0.46 & 68.5 \\
\hline & Ogawa $^{12)}$ & 0.72 & 0.67 & 0.68 & 0.68 & 12.6 \\
\hline & West & 0.16 & 0.28 & 0.15 & 0.14 & 358 \\
\hline & $\begin{array}{l}\text { Kondo, } \\
\text { Fujita }^{8)}\end{array}$ & 0.47 & 0.48 & 0.48 & 0.48 & 55.3 \\
\hline & $\begin{array}{l}\text { Walter } \\
\text { et al. } .^{15)}\end{array}$ & 0.52 & 0.56 & 0.56 & 0.55 & 36.5 \\
\hline & $\begin{array}{l}\text { Asano, } \\
\text { Fujita }\end{array}$ & 0.73 & 0.61 & 0.86 & 0.91 & 6.01 \\
\hline mi & nd & 0.639 & 0.655 & 0.623 & 0.619 & 7.52 \\
\hline
\end{tabular}

Delaware ${ }^{1)}$ are the values calculated in our laboratory by the Delaware method, and the errors are also compared with $\left(E_{M L}\right)_{1, \text { exp. }}$ except that by Onda et al.

obtained by the graphical method is plotted against $1 /\left(E_{M V}\right)_{1 / 2}$ for various values of $N_{P e}$, and $1 / E_{T}$ calculated by Eq.(43) is shown by the solid lines. The agreement between the results obtained by the graphical method and by the calculation with Eq.(43) is good. Therefore, by dividing the composition range into several regions (if it is necessary) and with the mean value of $\lambda$ in each region, the column efficiency $E_{T}$ for any degree of mixing of liquid on the plate can be estimated accurately by using Eq.(43) for a given value of the plate efficiency $\left(E_{M V}\right)_{1 / 2}$.

Many methods to estimate the plate efficiency have been proposed. By these methods, plate efficiencies were calculated for Manning's distillation data $^{10)}$, which had been used by Gerster ${ }^{7}$ to confirm 


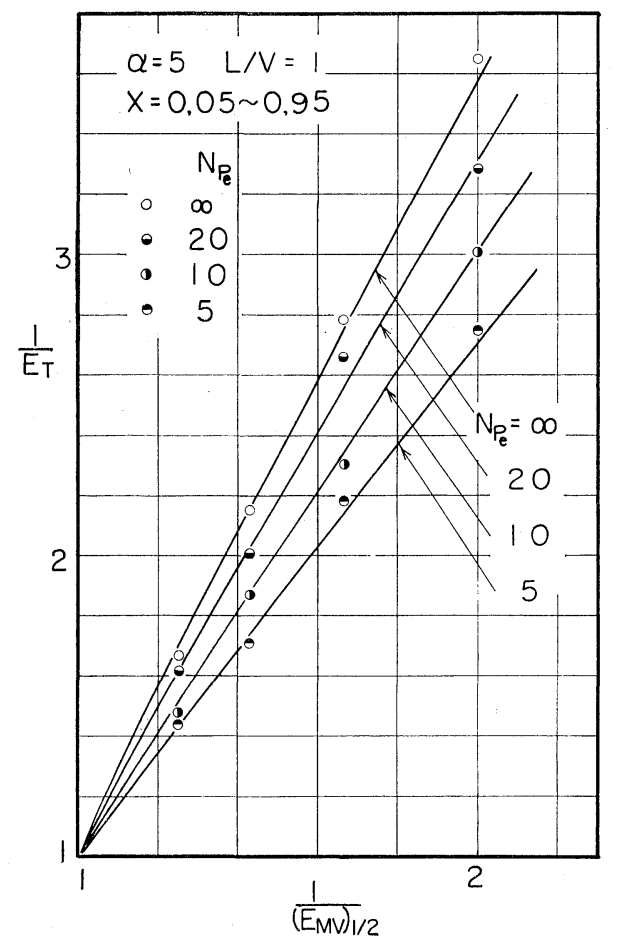

Fig. 7 Comparison of $1 / E_{T}$ calculated by Eq.(43) (solid lines) and those obtained by the graphical method (points)

their method ${ }^{1)}$, and are shown in Table 2. Gerster reported that plate efficiencies can be estimated accurately as shown in the column marked Delaware*. By our calculation, however, the method does not necessarily give the plate efficiencies in sufficient accuracy. Calculations by Asano and Fujita's meth$\mathrm{od}^{3,4)}$ and our method agree well with the experiments, and these methods make it possible to estimate plate efficiencies accurately.

\section{Plate Efficiency $\left(E_{M L}\right)_{1 / 2}$}

Although plate efficiency based on vapor composition is logical, plate efficiency based on liquid composition is often used in industry. The relation between plate efficiency $\left(E_{M L}\right)_{1 / 2}$ based on liquid composition and $\left(E_{M V}\right)_{1 / 2}$ based on vapor composition is derived as follows.

The slope of curve (22)' shown in Fig. 8 is given by Eq.(26) as

$$
a_{4}=\frac{y_{n}-y_{n-1}}{x_{n+1}-x_{n}}=\left(\frac{L}{V}\right) \frac{\lambda\left[\left\{2-\lambda\left(E_{M V}\right)_{1 / 2}\right\}+2 F\right]}{\lambda\left\{2-\left(E_{M V}\right)_{1 / 2}\right\}+2 F}
$$

And the slope of equilibrium curve and $\left(E_{M V}\right)_{1 / 2}$, respectively, are expressed as follows.

$$
\begin{aligned}
& m=\frac{y_{n}^{*}-y_{n}}{x_{n}-x_{n}^{*}} \\
& \left(E_{M V}\right)_{1 / 2}=\frac{y_{n}-y_{n-1}}{y_{n}^{*}-y_{n-1}}
\end{aligned}
$$

From Eqs.(47), (48) and (49), the plate efficiency $\left(E_{M L}\right)_{1 / 2}$ is derived as a function of $\left(E_{M V}\right)_{1 / 2}, \lambda$ and $F$.

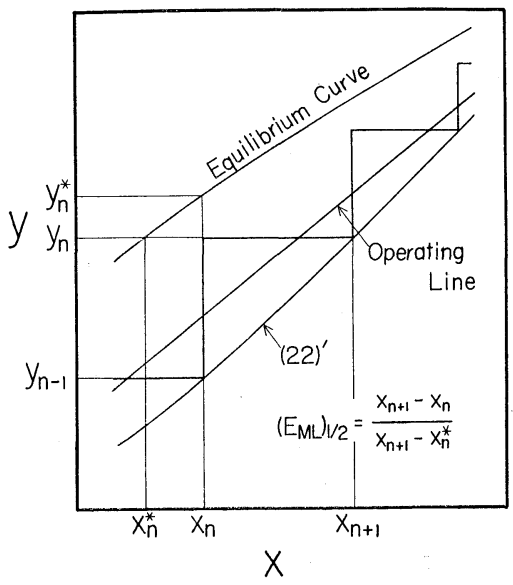

Fig. 8 Diagram to illustrate the plate efficiency $\left(\boldsymbol{E}_{M L}\right)_{1 / 2}$ based on liquid at the center of the plate

$$
\begin{aligned}
\left(E_{M L}\right)_{1 / 2} & =\frac{x_{n+1}-x_{n}}{x_{n+1}-x_{n}^{*}} \\
& =\frac{\left(E_{M V}\right)_{1 / 2}\left[\lambda\left\{2-\left(E_{M V}\right)_{1 / 2}\right\}+2 F\right]}{\left(E_{M V}\right)_{1 / 2}(\lambda-2)+2(1+F)}
\end{aligned}
$$

When liquid on the plate flows in plug flow, the mixing parameter $F$ is zero, and Eq.(50) becomes as follows.

$$
\left(E_{M L}\right)_{1 / 2}=\frac{\lambda\left(E_{M V}\right)_{1 / 2}\left\{2-\left(E_{M V}\right)_{1 / 2}\right\}}{\left(E_{M V}\right)_{1 / 2}(\lambda-2)+2}
$$

On the other hand, when the liquid on the plate is completely mixed, $F=\lambda\left(E_{M V}\right)_{1 / 2} / 2$, and Eq. (50) is rearranged as

$$
\left(E_{M L}\right)_{1 / 2}=\frac{\left(E_{M V}\right)_{1 / 2}}{\left(E_{M V}\right)_{1 / 2}+\frac{1}{\lambda}\left\{1-\left(E_{M V}\right)_{1 / 2}\right\}}
$$

Eq. (52) is the same relation as that derived for Murphree's plate efficiencies $\left(E_{M V}\right)_{1}$ and $\left(E_{M L}\right)_{1}$, which are based on the composition of vapor and of liquid, respectively.

\section{Conclusion}

For the limiting case where the liquid flows on the plate in plug flow, column efficiency $E_{T}$ for a fixed value of $\left(E_{M V}\right)_{1 / 2}$ is maximum when the reflux ratio is chosen to make the slope of the operating line equal to that of the equilibrium curve. For the general case, where any degree of mixing of the liquid on the plate may take place, column efficiency is given by Eq.(43) as a function of $\left(E_{M V}\right)_{1 / 2}, \lambda$ and $F$ (mixing parameter). As the degree of mixing increses, the value of $\lambda$ at the point which gives the maximum column efficiency for a fixed value of $\left(E_{M V}\right)_{1 / 2}$ increases. Eq.(43) can also be used to estimate $E_{T}$ accurately when the equilibrium curve is not a straight line, by dividing the calculation into several parts for $\lambda \leqq 1$, and $\lambda>1$. The plate efficiency $\left(E_{M L}\right)_{1 / 2}$ based on liquid composition at the center of the plate is given by Eq.(50) as a function of $\left(E_{M V}\right)_{1 / 2}, \lambda$ and $F$. 


\section{Nomenclature}

$A=$ cross-sectional area of the liquid segment on the plate $\left[\mathrm{cm}^{2}\right]$

$D \quad=$ flow rate of the top product

$[\mathrm{mole} / \mathrm{sec}]$

$D_{e} \quad=$ eddy diffusivity $\left[\mathrm{cm}^{2} / \mathrm{sec}\right]$

$\left(E_{M L}\right)_{1 / 2}=$ modified plate efficiency based on liquid at the center of the plate

$\left(E_{M V}\right)_{1}=$ Murphree's plate efficiency based on vapor in equilibrium with the liquid leaving the plate $\begin{aligned}\left(E_{M V}\right)_{1 / 2}= & \text { modified plate efficiency based on vapor in equi- } \\ & \text { librium with the liquid at the center of the plate }\end{aligned}$

$E_{O G}=$ point efficiency

$E_{T} \quad=$ column efficiency

$F \quad=$ function of $N_{P e}$ and $\eta$, presented by Eq. (10)

$L=$ liquid flow rate in the column [mole/sec]

$M \quad=$ number of practical plates

$m \quad=$ slope of equilibrium curve

$N=$ number of theoretical plates

$N_{P e} \quad=$ Peclet's number, $Z L / D_{e} A \rho_{L}$

$R \quad=$ reflux ratio

$r \quad=$ ratio of geometrical series in Eq.(38) and presented by Eq.(39)

$r^{*} \quad=$ ratio of geometrical series in Eq.(35) and presented by Eq.(36)

$=$ vapor flow rate in the column

$[\mathrm{mole} / \mathrm{sec}]$

$=z / Z$

$=$ mole fraction of more volatile component in liquid

$=$ composition of top product

$=$ liquid composition at the center of $n$-th plate

$=$ liquid composition in equilibrium with vapor from $n$-th plate

$y \quad=$ average mole fraction of more volatile component in vapor

$y_{n} \quad=$ vapor composition on $n$-th plate

$y_{n}^{*} \quad=$ vapor composition in equilibrium with $x_{n}$

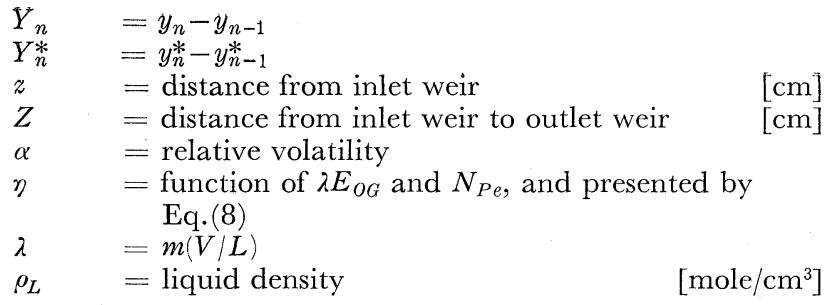

\section{Literature Cited}

1) AIChE Res. Comm: "Tray Efficiencies in Distillation Columns", Final Rept., Univ. Delaware (1958)

2) AIChE Res. Comm., "Tray Efficiencies in Distillation Columns", Final Rept., Univ. Mich. (1960)

3) Asano, K., and S. Fujita: Kagaku Kōgaku, 30, 403 (1966)

4) Asano, K., and S. Fujita: Kagaku Kōgaku, 30, 500 (1966)

5) Drickamer, H. G., and J. B. Bradford: Trans. AIChE, 39, 319 (1943)

6) Gerster, J. A.: Chem. Eng. Progr., 45, 716 (1949)

7) Gerster, J. A.: Ind. Eng. Chem., 52, 645 (1961)

8) Kondo, S. and S. Fujita: Kagaku Kōgaku, 16, 186 (1952)

9) Lewis, W. K.: Ind. Eng. Chem., 28, 399 (1936)

10) Manning, E., Jr., M. Stanley and G. P. Hinds, Jr.: Ind. Eng. Chem., 49, 2051 (1957)

11) O'Connell, H. E.: Trans. AIChE, 42, 741 (1946)

12) Ogawa, S.: Kagaku Kögaku, 22, 66 (1958)

13) Onda, K. and O. Kobayashi: Kagaku Kōgaku, 28, $823(1964)$

14) Onda, K., E. Sada, K. Takahashi and S. A. Mukhtar: AIChE Journal, 17, 1141 (1971)

15) Walter, J. F. and T. K. Sherwood: Ind. Eng. Chem., 33, 493 (1941)

16) West, F. B.: Ind. Eng. Chem., 44, 2470 (1952) 